\title{
Efecto Antimicrobiano del Aceite Esencial de Canela (Cinnamomum zeylanicum) sobre Cepas de Salmonella
}

\author{
Antimicrobial Effect of Cinnamon Essential Oil (Cinnamomum zeylanicum) on \\ SALMONELLA STRAins
}

\author{
Mayra Montero-Recalde ${ }^{1,2}$, Jessica Revelo I. ${ }^{1}$, Diana Avilés-Esquivel ${ }^{1}$, \\ Edgar Valle V. ${ }^{1}$, Deysi Guevara-Freire ${ }^{1}$
}

\section{Resumen}

\begin{abstract}
El efecto antimicrobiano del aceite esencial de canela (Cinnamomum zeylanicum) sobre cepas de Salmonella choleraesuis y Salmonella typhimurium fue investigado. El aceite de canela se obtuvo a través del método de destilación por arrastre de vapor y sometido a decantación, almacenándolo en refrigeración a $4{ }^{\circ} \mathrm{C}$. Se aplicó un diseño completamente al azar con cinco tratamientos $(10,30,50,70,90 \%$ de aceite de canela) y cinco repeticiones. La Concentración Mínima Inhibitoria determinada del extracto se verificó al 50, 70 y 90\% del aceite. En agar Mueller-Hinton se observó cero crecimientos de colonias con respecto a la Concentración Bactericida Mínima. La cepa Salmonella typhimurium presentó mayor sensibilidad al aceite de canela que la cepa Salmonella choleraesuis, en referencia al diámetro de los halos de sensibilidad.
\end{abstract}

Palabras clave: fitoterapia; Concentración Mínima Inhibitoria; Salmonella choleraesuis; Salmonella typhimurium; antibiograma; McFarland

\section{Abstract}

The antimicrobial effect of cinnamon essential oil (Cinnamomum zeylanicum) on strains of Salmonella choleraesuis and Salmonella typhimurium was evaluated. The cinnamon oil was obtained by the method of steam distillation, decanted, and stored at $4{ }^{\circ} \mathrm{C}$. A completely randomized design was applied with five treatments $(10,30,50,70$, $90 \%$ of cinnamon oil) and five replicates. The determined Minimum Inhibitory

\footnotetext{
${ }^{1}$ Facultad de Ciencias Agropecuarias, Universidad Técnica de Ambato, Cevallos, Tungurahua, Ecuador

${ }^{2}$ E-mail:ma.montero@uta.edu.ec
} 
Concentration of the extract was verified at 50, 70 and $90 \%$ of the oil. On Mueller-Hinton agar, zero colony growth was observed with respect to the Minimum Bactericidal Concentration. The strain Salmonella typhimurium presented greater sensitivity to cinnamon oil than the strain Salmonella choleraesuis in relation to the diameter of the halos of sensitivity.

Keywords: phytotherapy; Minimum Inhibitory Concentration; Salmonella choleraesuis; Salmonella typhimurium; antibiogram; McFarland

\section{INTRODUCCIÓN}

Los riesgos de contraer enfermedades al consumir productos de origen animal contaminados con bacterias resistentes como la Salmonella Typhimurium $y$ Choleraesuis son cada vez más frecuentes. Salmonella spp son bacterias Gram-negativas que causan retraso del desarrollo y disminución de la conversión alimenticia, y se presentan con alta morbilidad y presencia de lesiones intestinales y mortalidad (Talavera et al., 2011).

Una alternativa al uso, a veces indiscriminado, de antibióticos reside en la utilización de plantas medicinales o fitoterapia, la cual ha sido empleada en todo el mundo desde épocas remotas. El 67\% de las especies vegetales medicinales son provenientes de países en desarrollo (Ministério da Saúde, 2006), donde se requiere estudios más profundos sobre el uso de ingredientes activos presentes en plantas, que se pueden usar en forma de esencias, aceites y extractos, y que podrían minimizar o eliminar el uso de productos químicos artificiales, así como reducir el impacto de los residuos químicos en el ambiente y en productos animales como carne, leche y huevos (SENA, 2012). Diversas plantas y extractos son utilizados, además, como aditivos nutricionales para el control de enterobacterias en animales de producción (Veiga, 2008; Loya et al., 2009).

Los aceites esenciales obtenidos de las plantas han mostrado tener propiedades antimicrobianas, antioxidantes, antiparasitarias, antiinflamatorias, antidiarreicas y antimicóticas (Van-Zyl et al., 2004). Además, mejoran la conversión alimenticia y la palatabilidad de los alimentos, y estimulan las enzimas digestivas (Hernández et al., 2004; Giannenas et al., 2011). Estos productos son una alternativa viable al uso de aditivos artificiales y fármacos utilizados en la producción animal (Martínez et al., 2015). El aceite esencial de canela (Cinnamomum zeylanicum) es utilizado como bactericida gracias a su componente principal, el eugenol, presente en un 70-95\% (Husain et al., 1989; González, 2002). Con base en lo anterior, el objetivo de esta investigación fue obtener un producto natural y económico a base del aceite esencial de canela (Cinnamomum zeylanicum) para evaluar el efecto antimicrobiano en cepas certificadas de Salmonella choleraesuis y $S$. typhimurium.

\section{Materiales y Métodos}

La investigación se realizó en el laboratorio de bacteriología de la Facultad de Ciencias Agropecuarias de la Universidad Técnica de Ambato, Campus Querochaca, ubicada en el cantón Cevallos, Tungurahua, Ecuador, a $2750 \mathrm{msnm}$. El estudio se realizó en un ambiente controlado a $20^{\circ} \mathrm{C}$ y humedad relativa de $48 \%$, utilizando la cámara de flujo laminar para evitar contaminación.

\section{Material Vegetal y Bacteriano}

Como materia prima, se utilizó la corteza de canela (Cinnamomum zeylanicum), adquirida en un mercado de la ciudad de Riobamba, Ecuador. Se obtuvieron cepas certificadas de Salmonella enterica subsp 
entérica serovar Choleraesuis ATCC ${ }^{\circledR}$ $10708^{\mathrm{TM} *}$ y Salmonella enterica subsp enterica serovar Typhimurium ATCC ${ }^{\circledR}$ $13311^{\mathrm{TM}} *$.

\section{Aceite de Canela}

Se utilizaron $3 \mathrm{~kg}$ de corteza de canela, que fue sometida a un proceso de destilación por arrastre de vapor utilizándose $250 \mathrm{ml}$ de agua destilada. Se obtuvo $20 \mathrm{ml}$ de aceite esencial de canela.

\section{Aislamiento y Preparación del Inóculo}

Se aislaron las bacterias certificadas a partir de la técnica de siembra en estría por agotamiento en Agar MacConkey y se incubaron a $37^{\circ} \mathrm{C}$ por $24 \mathrm{~h}$. En la preparación del inóculo se utilizó el método del medio de cultivo líquido o de Kirby-Bauer, para lo cual se tomó en asa bacteriológica cinco colonias aisladas de cada una de las cepas certificadas y se las transfirió mediante un hisopo a $5 \mathrm{ml}$ de caldo cerebro corazón para ser incubadas a $37^{\circ} \mathrm{C}$ por $2 \mathrm{~h}$. Fueron estandarizadas al 0.5 de la escala de MacFarland a $620 \mathrm{~nm}$ en espectrofotómetro, obteniéndose $1.5 \times 10^{8}$ Unidades Formadoras de Colonias (UFC).

\section{Aceite Esencial de Canela - CMI y CMB}

Se obtuvo un total de $20 \mathrm{ml}$ de aceite esencial de canela. Se realizaron 5 diluciones: $10,30,50,70$ y $90 \%$ (v/v) con etanol al 25\% (Maiefski et al., 2009). Se transfirió 1 $\mathrm{ml}$ del inóculo estandarizado más $1 \mathrm{ml}$ de las cinco concentraciones del aceite esencial de canela de cada una de las cepas y se incubaron a $37^{\circ} \mathrm{C}$ durante $24 \mathrm{~h}$, estableciendo la concentración mínima inhibitoria (CMI). Esta fue valorada por la falta de turbidez en los tubos. La determinación de esta variable permitió la determinación de la concentración mínima bactericida (CMB), a través de la siembra de los tubos que no presentaron turbidez en agar MacConkey y su interpretación valorada a través del cero crecimiento de colonias en placa.

\section{Discos de Sensibilidad}

Se impregnó una gota para cada disco de sensibilidad con las cinco concentraciones del aceite esencial de canela y se refrigeraron por $24 \mathrm{~h}$ para evitar que el aceite se disemine por el agar.

La valoración de la actividad antibacteriana de las concentraciones de aceite esencial de canela y del control negativo (etanol al 99.8\%) se realizó mediante dos técnicas:

- Difusión en medio líquido: Se inocularon las cepas en tubos de ensayo con caldo Cerebro-Corazón y la turbidez fue comparada con la del tubo \#5 de la escala de McFarland. Se incubaron 10 tubos con un $1 \mathrm{ml}$ de caldo con la cepa respectiva y 1 $\mathrm{ml}$ de aceite de canela a $37^{\circ} \mathrm{C}$ por $24 \mathrm{~h}$ para obtener la Concentración Mínima Inhibitoria (CMI). La concentración con menor turbidez se sembró en medio agar para la determinación de la Concentración Mínima Bactericida (CMB).

- Difusión en disco agar: Se sembraron las cepas en la superficie del agar MuellerHinton con los discos de sensibilidad. Se incubaron a $37^{\circ} \mathrm{C}$ por $24 \mathrm{~h}$ y se evaluó el diámetro del halo de crecimiento con una regleta milimétrica Hiantibiotic ZoneScale.

\section{Resultados}

La interacción entre las concentraciones del aceite de canela y el crecimiento de las cepas Salmonella choleraesuis y typhimurium muestran un comportamiento definido a la razón de un incremento de la concentración y la turbidez reflejada (Cuadro 1). Los niveles de dilución de 10 y $30 \%$ en el caso de ambas cepas presentaron turbidez, refiriendo que existe un crecimiento bacteriano positivo, mientras que, en las concentraciones de 50, 70 y $90 \%$ no hubo turbidez, indicando ausencia de crecimiento bacteriano. 
Cuadro 1. Determinación de la concentración mínima inhibitoria (CMI) del crecimiento bacteriano enfrentado a cinco diluciones de aceite de canela (Cinnamomum zeylanicum)

\begin{tabular}{|c|c|c|c|c|c|c|}
\hline \multirow{3}{*}{ Cepas } & \multicolumn{5}{|c|}{ Diluciones del aceite de canela + etanol $99.8 \%$} & \multirow{3}{*}{$\begin{array}{l}\text { Control } \\
\text { negativo } \\
\text { (etanol } \\
99.8 \% \text { ) }\end{array}$} \\
\hline & $10 \%$ & $30 \%$ & $50 \%$ & $70 \%$ & $90 \%$ & \\
\hline & \multicolumn{5}{|c|}{ Turbidez } & \\
\hline $\begin{array}{l}\text { Salmonella } \\
\text { choleraesuis }\end{array}$ & + & + & - & - & - & + \\
\hline $\begin{array}{l}\text { Salmonella } \\
\text { typhimurium }\end{array}$ & + & + & - & - & - & + \\
\hline
\end{tabular}

La concentración mínima bactericida (Cuadro 2) muestra que en los tubos de 1 y 2 se presentó la formación de colonias, mientras que los tubos 3 , 4 y 5 no hubo crecimiento de colonias en el medio solido agar MacConkey; es decir, las concentraciones de 50,70 y $90 \%$ de aceite de canela no permitieron el desarrollo de las dos cepas. Asimismo, el etanol no mostró un efecto inhibitorio sobre las bacterias.

En el Cuadro 3 se observa que las concentraciones de 50, 70 y $90 \%$ de aceite de canela mostraron diferencia significancia $(p<0.001)$ con relación a las concentraciones de 10 y 30\% para Salmonella choleraesuis, en tanto que las concentraciones de 70 y $90 \%$ de aceite de canela mostraron diferencia significativa con las demás concentraciones para Salmonella typhimurium $(\mathrm{p}<0.001)$.

\section{Discusión}

El uso de aceites esenciales permite dar alternativas al uso de antibióticos que puedan crear resistencia y ser perjudiciales para la salud (Esquivel et al., 2010); entre ellos el aceite de la canela, que ha demostrado tener un efecto antimicrobiano eficaz (Shiva, 2007). Asimismo, se puede utilizar aceites esencia- les como antibióticos promotores de crecimiento debido a un componente en común que es el eugenol, el cual aumenta la secreción de enzimas digestivas y evita la proliferación de bacterias, mejorando el rendimiento a la canal (Marien et al., 2006).

Al analizar los resultados obtenidos por el método de difusión en agar, se puede indicar que esta metodología es adecuada para evaluar de manera cualitativa y cuantitativa la actividad antimicrobiana del aceite esencial de canela, tal como lo señala el NCCLS (2012). Esta técnica consiste en la medición del halo de inhibición del crecimiento bacteriano generado por un agente antimicrobiano.

En lo que respecta a la determinación de la Concentración Mínima Inhibitoria, se evidenció un efecto claramente marcado del aceite esencial de canela sobre el crecimiento bacteriano de las cepas en estudio. Fuselli et al. (2006) demostró incluso que concentraciones menores de aceite esencial (12.5\%) pueden reducir la CMI y la CMB. Este mismo comportamiento lo reporta Borboa et al. (2010) con aceites esenciales de Lippia palmeri, Thymus vulgaris y Cinnamomum zeylanicum en diluciones de 1:1, 1:5 y 1:10 $(\mathrm{v} / \mathrm{v})$, mostrando efecto inhibitorio in vitro sobre la bacteria Clavibacter michiganensis. 
Cuadro 2. Determinación de la concentración mínima bactericida (CMB) del crecimiento bacteriano enfrentado a cinco diluciones de aceite de canela (Cinnamomum zeylanicum)

\begin{tabular}{|c|c|c|c|c|c|c|}
\hline \multirow{3}{*}{ Cepas } & \multicolumn{5}{|c|}{$\begin{array}{l}\text { Tubos de ensayo con diluciones de aceite y cepas } \\
\text { bacterianas }^{1}\end{array}$} & \multirow{3}{*}{$\begin{array}{r}\text { Control } \\
\text { negativo } \\
\text { (etanol } \\
99.8 \% \text { ) }\end{array}$} \\
\hline & 1 & 2 & 3 & 4 & 5 & \\
\hline & \multicolumn{5}{|c|}{ Crecimiento } & \\
\hline $\begin{array}{l}\text { Salmonella } \\
\text { choleraesuis }\end{array}$ & + & + & - & - & - & + \\
\hline $\begin{array}{l}\text { Salmonella } \\
\text { typhimurium }\end{array}$ & + & + & - & - & - & + \\
\hline
\end{tabular}

Cuadro 3. Halos de sensibilidad (en $\mathrm{mm}$ ) de dos cepas bacterianas sometidas a cinco concentraciones de aceite de canela (Cinnamomum zeylanicum)

\begin{tabular}{|c|c|c|c|c|c|c|c|}
\hline \multirow{2}{*}{ Cepas } & \multicolumn{5}{|c|}{ Tratamientos } & \multirow{2}{*}{ ESM } & \multirow{2}{*}{$\begin{array}{c}\text { Valor } \\
\text { de P }\end{array}$} \\
\hline & $10 \%$ & $30 \%$ & $50 \%$ & $70 \%$ & $90 \%$ & & \\
\hline $\begin{array}{l}\text { Salmonella } \\
\text { choleraesuis }\end{array}$ & $11.4^{\mathrm{b}}$ & $14.8^{\mathrm{b}}$ & $19.0^{\mathrm{a}}$ & $18.8^{\mathrm{a}}$ & $21.6^{\mathrm{a}}$ & 0.89 & $<.0001$ \\
\hline $\begin{array}{l}\text { Salmonella } \\
\text { typhimurium }\end{array}$ & $14.6^{\mathrm{c}}$ & $21.2^{\mathrm{b}}$ & $26.0^{\mathrm{a}}$ & $20.6^{\mathrm{b}}$ & $29.4^{\mathrm{a}}$ & 0.81 & $<.0001$ \\
\hline
\end{tabular}

$a, b, c$ Medias con letras diferentes dentro de filas difieren significativamente $(p<0.05)$

En este mismo sentido, Caballero et al. (2016) demostraron que los aceites esenciales de clavo de olor (Syzygium aromaticum) y canela (Cinnamomum zeylanicum) a concetraciones de $0.05,0.10$ y 0.20 inhiben el crecimiento de microorganismos fúngicos como Aspergillus flavus. Los efectos reportados en estos estudios pueden estar relacionados con la presencia de eugenol y cimaldehído en los aceites esenciales, que actúan directamente sobre la membrana bacteriana inhibiendo el crecimiento de microorganismos fúngicos y bacterianos (Cava et al., 2012). Por otro lado, Tong et al. (2005) encontraron que los aceites esenciales pueden inhibir el ciclo del ácido tricarboxílico (TCA) del metabolismo de la respiración bacteriana, afectando el consumo de oxígeno de las bacterias, causando su muerte.

Alzamora et al. (2001) reportaron diámetros de halos de inhibición formados por el aceite esencial de canela para $S$. typhimurium de $30 \mathrm{~mm}$ y para $S$. enteritidis de $32 \mathrm{~mm}$, mientras que Solarte (2015) utiliza 10 cepas clínicas de $S$. typhimurium obtenidas de varias especies domésticas, donde el aceite esencial de canela formó halos de inhibición de 14.33 a $16.33 \mathrm{~mm}$; entretanto, en el presente estudio fueron de $21.6 \mathrm{~mm}$ para Salmonella choleraesuis y de $29.4 \mathrm{~mm}$ para 
Salmonella typhimurium. Sin embargo, Barros et al. (2016), en estudios realizados sobre el uso del aceite esencial de canela recomienda un uso restringido, debido a que su uso continuo puede ocasionar efectos tóxicos en la membrana de los glóbulos rojos en humanos.

\section{Conclusiones}

- Las cepas de Salmonella son sensibles a concentraciones de aceite esencial de canela a concentraciones de $50 \%$ o superiores.

- La cepa bacteriana Salmonella typhimurium presentó mayor sensibilidad al aceite de canela que la cepa Salmonella choleraesuis, en referencia al diámetro de los halos de sensibilidad.

\section{Literatura Citada}

1. Alzamora L, Morales L, Armas L, Fernández G 2001. Medicina tradicional en el Perú: actividad antimicrobiana in vitro de los aceites esenciales extraídos de algunas plantas aromáticas. Anal Fac Med 62: 156-161. doi: 10.15381/ anales.v62i2.4167

2. Barros F, Oliveira R, Alves F, Bezerra L, Martins J, Melo H, et al. 2016. Activity of essential oils of Piper aduncum anf and Cinnamomum zeylanicum by evaluating osmotic and morphologic fragility of erythrocytes. Eur J Integrative Med 8: 505-512. doi: 10.1016/j.eujim.2016.02.011

3. Borboa J, Rueda E, Acedo E, Ponce J, Cruz M, García J, Ortega M. 2010. Evaluación de la actividad antibacteriana in vitro de aceites esenciales contra Clavibacter michiganensis Subespecie michiganensis. Trop Subtrop Agrosyst 12: 539-547.
4. Caballero C, Villacorta L, Pretell C. 2016. Efecto del aceite esencial de clavo de olor (Syzygium aromaticum), canela (Cinnamomum zeylanicum) y su combinación sobre la acción antifúngica en Aspergillus flavus en agar chicha de maíz (Zea mays L.), variedad morado. Pueblo Continente 22(1): 123-132.

5. Cava R, Taboada A, Palop A, López A, Marin F. 2012. Heat resistance of Listeria monocytogenes in semi-skim milk supplemented with vanillin. Int J Food Microbiol 157: 314-318. doi: 10.1016/j.ijfoodmicro.2012.05.003

6. Esquivel P, Pedroza G, Sandoval N, Mata R, Mendoza L, Balderas I. 2010. Ensayo químico dirigido y estudio del efecto antimicrobiano in vitro de algunos condimentos empleados en la cocina mexicana. Rev Salud Públ Nutr 10: 7 (Resumen).

7. Fuselli S, García De La Rosa S, Gende L, Eguaras, Fritz R. 2006. Inhibición de Paenibacillus larvae empleando una mezcla de aceites esenciales y timol. Rev Argent Microbiol 38: 89-92.

8. Giannenas I, Skoufos J, Giannakopoulos C, Wiemann $M$, Gortzi O, Lalas S, Kyriazakis I. 2011. Effects of essential oils on milk production, milk composition, and rumen microbiota in Chios dairy ewes. J Dairy Sci 94: 5569-5577. doi: 10.3168/jds.20104096

9. González R. 2002. Eugenol: propiedades farmacológicas y toxicológicas. Ventajas y desventajas de su uso. Rev Cubana Estomatol 39: 139-156.

10. Hernández F, Madrid J, García V, Orengo JJ, Megías MD. 2004. Influence of two plant extracts on broilers performance, digestibility and digestive organ size. Poult Sci 83:169-174.

11. Husain A, Virmani P, Misra N. 1989. The major essential oil-bearing plants of India. Lucknow, India: Central Institute of Medicinal and Aromatic Plants (CSIR). 49 p. 
12. Loya A, González A, Rivera J. 2009. Prevalence of polypharmacy, polyherbacy, nutritional supplement use and potential product interactions among older adults living on the United StatesMexico border: a descriptive, questionnaire-based study. Drugs Aging 26: 423-436. doi: 10.2165/00002512200926050-00006

13. Maiefski M, Rupp M, Hermsen E. 2009. Ethanol lock technique: review of the literature. Infect Control Hosp Epidemiol 30: 1096-1108. doi: 10.1086/ 606162

14. Marien M, Nauwynck H, Duchateau L, Martel A, Chiers K, L Devriese, Froyman $R$, et al. 2006. Comparison of the efficacy of four antimicrobial treatment schemes against experimental Ornithobacterium rhinotracheale infection in turkey poults pre-infected with avian pneumovirus. Avian Pathol 35: 230-237. doi: 10.1080/03079450600711052

15. Martínez R, Ortega M, Herrera J, Garza J, Zárate J, Soriano R. 2015. Uso de aceites esenciales en animales de granja. Interciencia 40: 744-750.

16. Ministério da Saúde. 2006. A fitoterapia no SUS e o Programa de Pesequisa de Plantas Medicinais da Central de Medicamentos. Brasilia: Ministério da Saúde. Série B. Textos Básicos de Saúde. 147 p.

17. [NCCLS] National Committee for Clinical Laboratory Standars. 2012. Performance standars for antimicrobial disk susceptibility test. M02-A11 32(1). USA: NCCLS. 76 p.

18. [SENA] Servicio Nacional de Aprendizaje. 2012. Introducción a la indus tria de los aceites escenciales de pantas medicinales y aromáticas. Bogotá: Centro de Gestión de Mercados, Logística, TIC's. 87 p.

19. Shiva C. 2007. Estudio de la actividad antimicrobiana de extractos naturales y ácidos orgánicos. Posible alternativa a los antibióticos promotores de crecimiento. Tesis Doctoral. Barcelona España: Univ Autónoma de Barcelona. $184 \mathrm{p}$.

20. Solarte AL. 2015. Aplicación de aceites escenciales para el control de Salmonella typhimurium aislada de casos clínicos en diferentes especies animales. Tesis de Maestría. Córdoba, España: Univ de Córdoba. 28 p.

21. Talavera M, Varela J, Reyes $N$, Lagunas $S$, Carranza B, Alonso $M$, Velázquez V. 2011. Resistencia antibiótica de genotipos de cepas de Salmonella spp de cerdos sacrificados en rastros del Estado de México. Vet Méx 42: 269-276.

22. Tong $G$, Yulong $M$, Peng $G$, Zirong $X$. 2005. Antibacterial effects of the $\mathrm{Cu}(\mathrm{II})$ exchanged montmorillonite on Escherichia coli $\mathrm{K} 88$ and Salmonella choleraesuis. Vet Microbiol 105: 113122. doi: 10.1016/j.vetmic.2004.11.003

23. Van-Zyl RL, Seatlholo S, Van-Vuuren S, Viljoen A. 2004. The biological activities of 20 nature identical essential oil constituents. J Essen Oil Res 18: 129-133.

24. Veiga V. 2008. Divulgação estudo do consumo de plantas medicinais na região Centro-Norte do Estado do Rio de Janeiro/ : aceitação pelos pro fi ssionais de saúde e modo de uso pela população. Rev Bras Farmacogn 18: 308-313. doi: 10.1590/S0102-69 